\title{
Reunión de personalidades sobre \\ la crisis mundial y América Latina: \\ conclusiones
}

América Latina atraviesa por la crisis económica más severa que ha enfrentado en los últimos cincuenta años, como consecuencia de los profundos clesequilibrios de la economía internacional y de la acumulación de problemas no resueltos en el plano de sus estrategias de desarrollo y sus políticas económicas internas. La fuerte caída de los precios de los productos básicos, el recrudecimiento del pro. teccionismo en los centros industriales, las elevadas tasas de interés real que aún prevalecen en los mercados financieros internacionales, la violenta retracción del ingreso de créditos privados externos, luego de un periodo en que éstos aumentaron en forma extraordinarı, todos ellos aunados a un cúmulo de obstáculos cle origen interno, constituyen otros tantos factores que se han conjugado para generar agudas crisis de balance de pagos y declinaciones importantes en los ritmos de crecimiento - $\mathrm{e}$ incluso en Ios niveles absolutos de actividad económicos- en la mayor parte de los países de la región.

La crisis economica internacional ha estado ligacla en forma estrecha a la desfavorable evolución económica reciente en los países industrializados de economía de mercado. La caída de la actividad económica en éstos no sólo representa una profunda inflexión en el prolongado ciclo expansivo que se inició en la postguerra, sino que refleja también los efectos de marcádos desequilibrios estructurales acumulados por esos países a través de los años. Pero en la crisis de los países industrializados han influido también las muy res-

* La Secretaría Ejecutiva de la cepal convocó a un grupo de personalidades de diversos países latinoamericanos a fin de analizar el impacto de la crisis económica internacional sobre América Latina y sus posibles soluciones. Las personalidades invitadas intervinieron a titulo estrictamente personal, sin comprometer la posición de los gobiernos de sus respectivos paises o de las instituciones a las cuales se encuentran vinculadas. La reunıón tuvo lugar en Bogotá, entre los días 18 y 21 de mayo de 1983, y fue inaugurada por el Presidente de Colombia, doctor Belisario Betancurt. A continuación se consignan las conclu. siones de la reunión. 
trictivas políticas monetarias que ellos han aplicado, en un contexto que se caracteriza además por grandes déficit fiścales. Como consecuencia, las tasas de interés han alcanzado niveles sin precedentes. Estas altas tasas constituyen el principal obstáculo para lograx una recuperación vigorosa y duradera de la economía internacional, y han abultado extraordinariamente el servicio de la deuda externa de los países latinoamericanos. Por otra parte, al proyectarse sobre las tasas internas de interés y conjugarse en algunos países con políticas de exagerada liberación financiera, han contribuido a deteriorar la solvencia de las empresas y a dificultar la recuperación de la actividad económica y del empleo en la mayoría de los países de la región.

La contracción del comercio exterior de los países latinoamericanos se ha manifestado tanto en el intercambio con el resto del mundo como -y aún en mayor proporción- en el comercio intrarregional. Así, cuando más se precisa la cooperación intralatinoamericana, ella está siendo víctima de los efectos combinados de la crisis económica internacional, y de factores internos que erosionan el proceso, sumándose a las fuerzas recesivas que actúan en la región. Un motivo de especial preocupación radica en las crecientes restricciones al comercio recíproco que se han ido imponiendo en todas las agrupaciones subregionales de integración dentro de América Latina.

Es preciso reconocer, además, que las deficiencias de las políticas económicas aplicadas por algunos países de la región no han sido ajenas a la grave situación que hoy éstos enfrentan. De allí que, junto con adoptar las medidas inmediatas que se requieran para encarar la crisis, los países deberán avanzar gradualmente hacia estilos de desarrollo que no sólo concuerden mejor con el contexto internacional más restrictivo y con las crecientes y legítimas aspiraciones de equidad social que probablemente prevalecerán en el futuro, sino que también se basen en mayor medida en el esfuerzo interno.

Para hacer frente a estos desafíos, es preciso introducir cambios profundos en el orden económico internacional vigente, de conformidad con los términos planteados reiteradamente por los países en desarrollo en diversos foros internacionales. En lo inmediato, es fundamental, además, que los principales países desarrollados pongan en marcha vigorosos programas de reactivación económica a través de acciones coordinadas que eviten el surgimiento de nuevas presiones inflacionarias. Esta política de reactivación deberá incorporar, asimismo, medidas que contemplen los legítimos intereses y aspiraciones de los países en desarrollo, y que permitan que éstos desempeñen el papel dinámico que les corresponde en la economfa internacional.

Estos últimos países, a su vez, deberán decidir acciones encaminadas a reactivar sus propias economías, aprovechando tanto las 
oportunidades que ofrezca la recuperación de la economía internacional, como el aumento de la demanda interna de cada país y de la región en su conjunto. De la misma manera, se precisan cambios importantes en la conducción de la política económica interna de la mayoría de los países latinoamericanos, orientados a adecuarla a las nuevas circunstancias y a producir las transformaciones estructurales necesarias para promover una mejor distribución del ingreso $y$, con ello, el logro del necesario consenso social.

Todo esto exige una acción más éficaz y oportuna del Estado, no sólo para enfrentar la crisis, sino para asegurar que, una vez superada ésta, las economías retomen el camino del crecimiento económico sobre bases más sostenidas equitativas y dinámicas. Para ello se deberá hacer un uso más eficaz de los instrumentos monetarios, fiscales y cambiarios, sanear los mercados financieros internos, dotar al sector público de fuentes no inflacionarias y hacer más equitativa la distribución, tanto de Ios sacrificios derivados del proceso de ajuste como de los frutos del desarrollo económico.

Los países de la región han expresado su firme voluntad de hacer frente a los compromisos externos adquiridos. Sin embargo, aún a costa de sacrificios extremos, muchoside ellos no estarían en condiciones de cumplir los servicios de su deuda externa en los términos en que ésta ha sido contratada. Además, algunas de las soluciones alcanzadas hasta ahora parecen ser arreglos que podrian dar pie a nuevas y más graves dificultades. Por otro lado, en los procesos de renegociación, i los bancos comerciales privados han aumentado desmedidamente șus comisiones y recargos en los préstamos que refinancian.

Las instituciones financieras internacionales existentes carecen de facultades y recursos suficientes para ofrecer soluciones que concilien los intereses fundamentales de deudores y acreedores. Por otra parte, las condiciones asociadas al suministro de ayuda de emergencia a los países endeudados constituyen de hecho un arbitrio para racionar sus magras disponibilidades. Dichas condiciones están conduciendo a una contracción aún mayor del comercio internacional, lo que agrava la crisis mundial y aumenta los costos sociales de ésta para nuestros países.

Se enfrenta así una situación intrínsecamente inestable. Cada vez son más los que creen que urge alcanzar una solución real y duradera que contribuya a restituir la estabilidad de las relaciones internacionales. Esto de ninguna manera significa postular un enfrentamiento colectivo entre los países deudores y sus acreedores, ni tampoco propiciar una refinanciación conjunta de las deudas externas de países que se encuentran en situaciones muy diversas. Es esencial, sin embargo, adoptar iniciativas políticas al más alto nivel posible, con miras a crear conciencia en los dirigentes de la comunidad internacional, tanto de las graves consecuencias que podrían 
derivarse de una contracción adicional de la actividad económica en la mayoría de los países latinoamericanos, como de la necesidad de destinar recursos adicionales y crear condiciones diferentes para que éstos puedan refinanciar en forma adecuada sus deudas. Como lo ha comprendido acertadamente el Presidente del Ecuador, doctor Osvaldo Hurtado, es de vital importancia que esas iniciativas partan de una acción concertada de los gobiernos de la región, ya que la dramática situación actual no sólo los afecta a ellos y a los acreedores externos, sino que limita fuertemente el bienestar y perspectivas de centenares de millones de latinoamericanos.

Por estas razones, es fundamental que se creen mecanismos adicionales a los existentes, con el fin de configurar un marco internacional más adecuado a los procesos de renegociación de la deuda. Este debería incluir la participación de los organismos financieros internacionales, de los bancos privados y de las autoridades financieras de los países acreedores, y debería considerar la provisión de recursos adicionales para hacer frente, tanto a los compromisos del servicio de la deuda como a las necesidades mínimas de financiación del comercio y del desarrollo. Al mismo tiempo, traducirse en plazos compatibles con la naturaleza de los créditos y rebajas sus. tanciales en las tasas de interés, y lograr asimismo que los costos del proceso de ajuste internacional se distribuyan en forma mucho más equitativa entre los países y bancos acreedores y los países deudores.

Junto con lo anterior, debe reconocerse que los problemas de fondo del balance de pagos no serán resueltos en definitiva si no se crean en el comercio internacional condiciones, especialmente en materia de precios y de apertura de mercados, que hagan posible a los países de la región obtener los recursos externos necesarios para hacer frente al servicio de su endeudamiento.

Es conveniente también reexaminar el considerable potencial que ofrece la cooperación intrarregional, no sólo como instrumento para mitigar los efectos de la recesión internacional y de las inciertas perspectivas de la economía mundial, sino también para coadyuvar a la adopción de estrategias nacionales de desarrollo adecuadas a las nuevas circunstancias. En este contexto, urge emprender acciones concretas que eviten un mayor deterioro en el grado de interdependencia económica ya alcanzado dentro de las agrupaciones subregionales existentes, y que no sólo pongan término sino que, también permitan invertir las perniciosas tendencias a imponer restricciones adicionales al comercio recíproco que se han venido observando en los últimos tiempos. Asimismo, es preciso abordar las distintas modalidades de cooperación que podrian ensayar los países latinoamericanos con el mayor realismo y flexibilidad posibles. Uno de los aspectos de los procesos regionales y subregionales de integración sobre el cual se podría decidir acciones inmediatas 
es el fortalecimiento de los sistemas de pagos recíprocos, a fin de promover más altos niveles de comercio intrarregional.

Por otra parte, las políticas de apoyo externo necesarias para aliviar los problemas de balance de pagos de los países latinoamericanos deben ir acompañadas de medidas internas adecuadas. En el corto plazo, estas medidas deberían propiciar la recuperación de la actividad económica de modo de preservar, a lo menos, los niveles básicos de empleo y de consumo ya alcanzados, teniendo en cuenta, al mismo tiempo, los permanentes objetivos de la lucha antinflacionaria.

Tanto las medidas que se adopten en el plano interno como las políticas nacionales diseñadas para enfrentar la crisis, deberán concebirse a la luz de los objetivos, aspiraciones y propuestas que los países latinoamericanos -y los países en desarrollo en generalvienen planteando desde hace largo tiempo en diversos foros internacionales, con miras a promover una reestructuración profunda del orden económico internacional, que les permita una participación más equitativa y más dinámica. 